УДК 316

$10.17213 / 2075-2067-2020-5-118-126$

\title{
ГОСУДАРСТВЕННОЕ РЕГУЛИРОВАНИЕ ОБЩЕСТВЕННОГО ПРИЗРЕНИЯ В ДОРЕВОЛЮЦИОННОЙ РОССИИ
}

\author{
(C) 2020 г. Е. Л. Шилкина*, Д. И. Сидорова ${ }^{* *}$
}

"Ростовский государственный университет путей сообщения, 2. Ростов-на-Дону, Россия

** Институт сферы обслуживания и предпринимательства (филиал), Донской государственный технический университет, г. Шахты, Россия

Целью исследования является выявление основных тенденщий государственного регулирования общзественного призрения в дореволюиионной России на основе анализа исторического опыта в сфере минимизации социальной эксклюзии людей с ограничениями здоровья.

Методологическая база исследования. Публикация подготовлена исходя из общенаучного принципа объективности, обязывающего видеть за субъективными коллизиями в политике объективные условия, в которых реализуется сочиальное управление. На основе принципов социального и исторического детерминизма с помощьью методов структурного анализа выделены системообразующие черты, определяющие субстанциональную сущность характер и функиии государственного управления в сфере регулирования прочессов инвалидизации общества и общественного призрения.

Результаты исследования. Появление первых государственных учреждений придало организованный и мотивированный характер сочиальной деятельности. Однако такая помощь оказывалась очень ограниченно и зачастую несвоевременно. К тому же только увечные военнослужащие могли относиться к инвалидам, в то время как другие люди, состояние здоровья которых невозможно восстановить, были лишены поддержки. В отличие от Западной Европь, в России не сложилась устойчивая комплексная система благотворительной помощчи, в которой государство, иерковь и города выступали бы партнерами в деле благотворительности.

Перспективу исследования составляет дальнейший сочиологический анализ отечественного опыта государственного управления процессами социальной интеграции инвалидов.

Ключевые слова: государственное управление; общественное призрение; государственная благотворительность; инвалид; правительство; пенсия; социальная поддержка.

\section{STATE REGULATION OF PUBLIC CHARITY IN PRE-REVOLUTIONARY RUSSIA}

\author{
(C) 2020 E. L. Shilkina*, D. I. Sidorova** \\ "Rostov State Transport University, Rostov-on-Don, Russia \\ **Institute of Service and Entrepreneurship (branch), \\ Don State Technical University, Shakhty, Russia
}

The purpose of the study is to identify the main trends of state regulation of public charity in pre-revolutionary Russia based on the analysis of historical experience in the field of minimizing social exclusion of people with disabilities. 
Methodological basis of the study. The publication was prepared on the basis of the general scientific principle of objectivity, which obliges to see subjective conflicts in politics as objective conditions in which social management is implemented. Based on the principles of social and historical determinism, using structural analysis methods, systemic-forming features are identified that determine the substantive nature of the nature and functions of public administration in the field of regulating the processes of disabled society and public charity.

The results of the study. The emergence of the first state institutions gave an organized and motivated character to social activities. However, such assistance was very limited and often untimely. But the main problem was that only eternal servicemen could relate to the disabled, while other people whose health could not be restored were deprived of support. Russia, unlike Western Europe, has not developed a sustainable comprehensive system of charitable assistance, in which the state, church and cities acted as partners in the cause of charity.

The prospect of the study is a further sociological analysis of the domestic experience of state management of the processes of social integration of persons with disabilities.

Key words: public administration; public contempt; state charity; disabled person; government; pension; social support.

Введение. Цивилизационные трансформации, протекающие в современном обществе, требуют пересмотра подходов к проблемам инвалидности. Отношение к инвалидности как обществе в целом, так и рамках государственной политики претерпело принципиальные изменения.

В рамках государственной политики произошел кардинальный переход от медицинской модели инвалидности к социальной, в русле которой инвалидность интерпретируется как проблема общества.

В соответствии с социальной моделью решение проблем инвалидности требует государственного вмешательства, поскольку она является следствием состояния окружающей среды, неприспособленной к нуждам людей с ограничениями здоровья. Социальная модель требует создания для данной категории граждан максимально благоприятных условий для преодоления социальной эксклюзии и интеграции в общество.

Задачи минимизации социальной эксклюзии людей с ограничениями здоровья требуют поиска путей совершенствования государственной политики, адекватных современным цивилизационным требованиям, а также учитывающих исторический опыт в данной сфере. Это обусловливает необходимость изучения государственного регулирования общественного призрения в исторической ретроспективе.
Институализация государственного призрения в России. С приходом к власти Петра I в стране происходят радикальные преобразования в сфере общественного призрения. Путешествуя по Европе, он знакомится с существующими в ней моделями государственной благотворительности и стремится внедрить все полезное в России. Результатом деятельности Петра I было более трех с половиной тысяч указов, касающихся организации государственного призрения, борьбы с нищенством и тунеядством, запрета подаяния. Указом 1691 года предписывалось забирать «гулящих» людей, просящих милостыню, и рассылать по месту жительства, а в случае вторичной поимки «бить батогами» и ссылать в Сибирь. За подаяние нищему на виновных накладывался штраф до пяти рублей. Проводимая в стране политика секуляризации монастырских владений способствовала установлению организационного контроля за деятельностью церкви и определению новых направлений её деятельности в деле общественного призрения. Так, участие в Северной войне привело не только к людским потерям, но и к большому количеству лиц, получивших увечья.

Именно в это время в России начали называть инвалидами немощных старых солдат, пострадавших во время военных действий и неспособных служить. Заботой госу- 
даря стало устройство в монастырях лазаретов для инвалидов, не имеющих своего дома и средств к существованию. Уход за ранеными осуществляли монахи, получая за это право проживать и питаться в монастыре. Инвалиды получали жалование из монастырских доходов. Отставные офицеры использовались для подготовки новобранцев, сбора припасов и кормов для армии, а нижние чины в качестве охранников. Однако стремление Петра I перенести заботу о нищих и инвалидах в разряд государственных задач, взяв за основу опыт западных стран, привело к недопониманию не только со стороны простых людей, предпочитающих организованному призрению милостыню, но и представителей привилегированных сословий и духовенства.

Монтескьё, изучая деятельность Петра I, упрекал его за недооценку своего народа, считая, что не следует изменять установленные народом обычаи и нравы посредством законов, лучше изменять их путем внедрения иных нравов и обычаев [1]. Оказалось невозможным за такой короткий срок создать европейскую систему призрения в стране без учета всех тех предпосылок, в которых эта система создавалась в Европе, и на создание которой западный мир потратил несколько столетий. «Это все равно, что пожелать увиденные западные вековые плоды просвещения в одну минуту присвоить своему народу», - считал В.Г. Белинский [2, с. 39].

После смерти Петра Великого большая часть задуманного практически осталась на бумаге, а сорокалетний период смены власти в России ознаменовался законодательным спадом в области призрения и усилением наказания за нищенство. Только с приходом на царствование Екатерины II наметились заметные перемены в области общественного призрения. Продолжая политику Петра I в области общественного призрения, Екатерина в первый год своего правления издает указ о строительстве специальных домов для душевнобольных и назначения служителями при них «отставных солдат, добрых и исправных». Параллельно с проведением губернской административной реформы по приказу императрицы создаются приказы общественного призрения в каждом губернском городе с возложением на них обязанностей по открытию, содержа- нию и надзору за сиротскими, инвалидными и работными домами, богадельнями.

Проведенная секуляризация церковных земель позволила пополнить государственную казну и закрыть солдатские богадельни в монастырях. Отслуживших военных направляли в указанные города на местожительство, где они получали назначенное жалованье. Затем к концу XVIII века была предпринята попытка организовать инвалидные роты с использованием их на легких работах, но они оказались неэффективными и были упразднены. После этого неспособных к военной службе оставляли при своих гарнизонах на нестроевые должности, а требующих постоянного ухода размещали по благотворительным заведениям и инвалидным домам. Если же не было мест в этих заведениях, то заботу об инвалидах поручали благонадежным лицам с оплатой из казны. Государство также брало на себя расходы на содержание солдатских жен и вдов, не способных работать, отправляя их на поселения, в женские монастыри или богадельни и оплачивая из государственной казны расходы на их содержание.

Таким образом, Екатерина II, являясь сторонницей просвещенного абсолютизма и продолжательницей дела Петра Великого, заботившаяся о быстрой цивилизации России, создала в стране ряд благотворительных учреждений призрения по европейским образцам.

Отстав от Европы почти на полтора столетия, Россия за короткий период смогла наверстать упущенные позиции в социальной сфере, по крайней мере, в Петербурге и Москве. Во всяком случае, можно сказать, что Екатерина Великая смогла заложить фундамент в деле социального призрения.

Спустя почти полтора века после того, как Россия отстала от Европы, она за короткое время добилась упреждающего статуса, но только в двух столицах.

По мнению многих отечественных историков, политика непредсказуемого Павла I, считавшего свою власть безграничной, характеризуется желанием ликвидировать установленные порядки в период правления его матери Екатерины. Так, например, самостоятельность приказов была упразднена и передана государственным властям, их сменили департаменты и врачебные коллегии, руководство которыми было возложено 
на его супругу Марию Федоровну и её канцелярию. Впоследствии этот орган получил название «Ведомство учреждений императрицы Марии». C именем императрицы связано создание новых благотворительных учреждений, ведомств, сиротских домов, первых училищ для глухонемых и слепых детей. При проведении военных реформ Павел I учредил лазареты при полках, в которых лекари должны были сдать экзамен в Медицинской коллегии, а отставные солдаты из-за увечий или прослужившие более двадцати пяти лет получили право на пенсию с содержанием в инвалидных ротах. До этого указа отставные солдаты-инвалиды оказывались предоставленными самим себе, занимаясь либо нищенством, либо грабежами.

Будучи уже императором, Павел I принял решение открыть в Чесменском дворце Екатерины II богадельню для инвалидов-воинов, но из-за возникших проблем с водоснабжением проект не был реализован. Лишь через тридцать лет богадельня была открыта для инвалидов и ветеранов Отечественной войны 1812 года. Находившиеся здесь инвалиды были на полном государственном обеспечении.

Формирование комплексной системы государственной и частной благотворительной помощи. Александр I, став императором после смерти своего отца Павла I, оставил свой след в развитии общественного призрения, основав в 1802 году Императорское Человеколюбивое общество, основным назначением которого являлось оказание нуждающимся «вспоможения всякого рода» за счет государственной казны и пожертвований частных лиц, в том числе и членов императорской семьи. Так, к примеру, императором из личных средств было выделено почти сорок тысяч. Интересен и тот факт, что монаршие щедроты за 18 лет (1816-1914 гг.) составили 9 млн. рублей, а частные пожертвования за этот же период - 106 млн. рублей. Напрашивается вывод: в деле оказания помощи нуждающимся роль государства не являлась выдающейся, о чем свидетельствуют данные о затратах на дело общественного призрения в размере 0,09-0,35 рубля на душу населения [3].

Правительство поощряло богатых людей делать всевозможные пожертвования, именно благотворительность открывала широкие воз- можности для получения государственных чинов, орденов и различных сословных привилегий. Александр I самых достойных членов общества награждал именными знаками с девизом: «Возлюби ближнего как самого себя», а в 1828 году Николай I своим указом вводит звание «Почетный попечитель» для граждан, сделавших крупные пожертвования.

Уже к 1913 году Общество объединяло около трехсот благотворительных учреждений по всей стране с установленными четкими правилами их устройства и функционирования с годовым бюджетом более 3,5 млн. рублей [4].

Немаловажен и тот факт, что Александр I не только продолжил создание инвалидных рот, начатое его отцом императором Павлом, но и провел их реформирование. В 1811 г. своим указом Александр I повелевает «инвалидные роты и команды обратить на пользу службы», а всех инвалидов именовать «военными инвалидами» и подразделить на подвижных, служащих и неспособных. Подвижные и служащие несли караул в гарнизонах, охраняя важные объекты и арестантов, занимались обслуживанием лазаретов, кухонь, казарм, конюшен. Инвалиды получали жалованье, «мундирные вещи и провиант», на обзаведение хозяйством им выделялось единовременно 50 рублей. Нетрудоспособные и нуждающиеся в уходе определялись в богадельни. Однако архивы сохранили жалобы на высочайшее имя, написанные инвалидами нижних чинов о несправедливости властей и с просьбой «... поуважать их заслуги, оказать им покровительство, сложить налоги, не следующие с них по закону», что являлось вполне типичным отражением отношения власти к инвалидам войны [5, с. 226].

Война 1812 года внесла коррективы в развитие призрения к военным инвалидам. Такой организацией стал созданный в 1814 году Комитет о раненых для призрения только высших чинов армии, пострадавших во время войны, а также членов их семей: вдов, сирот, матерей. Следующим шагом на пути развития деятельности Комитета стало покровительство нижним чинам, героям Отечественной войны, основу которого заложил П.П. Пезаровиус, создатель и редактор газеты «Русский инвалид», издаваемой с 1813 года. 
Образовавшийся у него инвалидный капитал в сумме 395 тысяч рублей по указу государя был передан в распоряжение Комитета вместе со списком 1200 инвалидов нижних чинов, получающих от него пенсии. И уже в феврале 1816 года это право распространялось и на других отставных и раненых нижних чинов, но члены их семей покровительством не пользовались.

В последующие годы Комитет финансировался главным образом за счет благотворительных пожертвований, аренды земель, благотворительных балов, лотерей, аукционов. Так, Николай Стародымов приводит один из примеров прецедента проведения французской колонией благотворительного аукциона в пользу семей погибших и раненых солдат с получением дохода почти в 42 тысячи, из которых только половина пошла на нужды семей инвалидов, а остальная нуждающимся французам. При затратах в 12,5 тыс. рублей французы не только окупили свои расходы, но и оказали поддержку своим соплеменникам за счет русских. Такая лицемерная «благотворительность» очень смахивает на фарисейство [6].

Уже к концу 1840 года инвалидный капитал составлял почти 4,2 миллиона рублей серебром, но коррупция начала разъедать благородный замысел, так директор канцелярии комитета А.Г. Политковский был уличен в воровстве почти 1,2 млн. рублей, подделывая документы, завышая суммы, подлежащие выдаче инвалидам, фальсифицируя дела инвалидов, которым якобы требовалась помощь, хотя из такой огромной суммы лишь $20 \%$ шло на поддержку нижних чинов [7].

Николаевская эпоха правления ознаменовалась спадом благотворительности, бессилием правительства справиться с последствиями войны. Нижним чинам назначались единовременные пособия, их определяли в тюремные надзиратели и в качестве сторожей при памятниках, на городских заставах.

У В. Гиляровского можно найти такие строчки: «... унтер командовал инвалиду у шлагбаума: - Подвысь!.. Инвалид гремел цепью шлагбаума». Да и у А.С. Пушкина в «Дорожных жалобах» упоминается «непроворный инвалид».

За тридцать лет правления Николая I со службы уволилось свыше 450 тысяч чело- век. Пытаясь защитить столицы от наплыва отставных солдат, не имеющих средств к существованию, государь своим указом 1851 года разрешал оставаться в Санкт-Петербурге и Москве лишь тем, кто имел возможность содержать себя «постоянными занятиями», что позволило сократить количество обращений за помощью и количество неимущих инвалидов в столицах. Те же, кто не мог рассчитывать на родственников или благотворителей, вынуждены были заниматься нищенством. И.Г. Прыжов в своих исследованиях писал о том, что роскошь преклонить голову в богадельне или приюте старым солдатам, слепым и безруким, блуждающим по церквам, по похоронам, лавкам, не для них. В богадельни попадают не хромые и слепые, а случайные: молодые и здоровые [8].

Для борьбы с нищенством Николай I создает «Комитет о просящих милостыню», задачей которого было оказание благотворительной помощи бедным. Реальные инвалиды получали медицинскую и материальную помощь, их определяли на службу в присутственные места, а те, кто не работал по лености, направлялись в работные дома. По словам А. Бахтиярова, на самом деле эти дома представляли собой клоаку, где никто не работал и где царило пьянство [9].

Военные перемены 60-70-х годов содействовали созданию новой системы поддержки нижних чинов. После введения 6-летнего срока службы правительство сняло с себя ответственность об отставниках, получивших право селиться на казенных землях и пособие в размере 40 рублей на обзаведение, и направило свое внимание на потребности инвалидов, утративших способность к труду в результате службы. В соответствии с положением 1867 года им назначалось пособие в размере трех рублей в месяц. Такая сумма, получаемая главой семьи, не только лишала надежды обзавестись собственным хозяйством, но и обрекала на бедность и бесправность.

Солдаты-инвалиды часто даже не подозревали, что могут воспользоваться помощью Александровского комитета. Только после публикации и передачи выдержек из существующих законов были предоставлены льготы нижним чинам, особенно тем, кто был ранен в ходе русско-турецкой войны 1877-1878 гг., приписанн к обществам, но не воспользовал- 
ся земельным наделом. И к концу XIX века таких инвалидов уже числилось более 30 тыс. человек

Что касается инвалидов, проживающих в сельской местности, то забота о них возлагалась на сельские общины, регулирующие хозяйственную и бытовую жизнь деревни. По решению общины назначались опекуны нетрудоспособным членам, что считалось мирской повинностью и законодательно было закреплено [10]. Принявшему в свою семью инвалида с предоставлением питания общиной определялась плата, возможность освобождения от ряда повинностей либо отвода дополнительного земельного участка.

Государственное регулирование общественного призрения в пореформенные годы. Но крестьянская реформа 1861 года, о которой писал Н. Некрасов: «Порвалась цепь великая, порвалась и ударила одним концом по барину, другим - по мужику», не повлекла за собой гражданское равноправие крестьян, а напротив, привела к тому, что большинство крестьян осталось без денег и наделов, которые можно было получить у барина по закону, заплатив за них. В сложившейся ситуации помощь немощным и инвалидам оказывалась за счет средств бедняков, входящих в состав сельских обществ: чем беднее общество, тем больше нуждающихся и тем меньше средств для оказания поддержки. Российская империя не выделяла и гроша на их материальное обеспечение. Это привело к тому, что в поисках лучшей жизни тысячи крестьян, сорванных с земли, неприкаянных, кинулись в город, пополнив армию нищих.

Сегодня можно встретить ряд публикаций, расписывающих царскую Россию как преуспевающее патерналистское государство, в котором добросердечные помещики заботились о собственных крестьянах. Однако, многие исторические источники свидетельствуют об обратном. Так, например, Л.Н. Толстой в своей статье «Голод» основными причинами его считал подати, малоземельность и закабаленность крестьян помещиками. Не только Л. Толстой, но и А. Чехов описывал нерадостную картину жизни работяг, их «испитые, истасканные, битые» лица, навсегда утратившие тепло...». Писатель В.Г. Ко- роленко в 1890-х годах сам принимал участие в организации столовых для голодающих и выдаче продовольственных ссуд.

Следовательно, можно сказать, что в дореволюционной России государственную социальную поддержку могли получать только чиновники и высшие воинские чины, а на крестьян, представителей низших чинов, рабочих и престарелых она не распространялась. Но под давлением народных волнений в 1903 году правительство приняло закон об ответственности предпринимателей за увечья, которые рабочие получали на производстве, правда, это было крайне трудно доказать из-за расплывчатых формулировок правовых норм, высоких судебных издержек, рабочей неграмотности и бюрократических судебных разбирательств. Принятый в 1912 году закон о страховании рабочих от несчастных случаев охватывал лишь 15\% от общего числа рабочих в России.

Интересен тот факт, что Всероссийская конференция РСДРП, проходившая в этом же году, была посвящена рассмотрению разработанной Лениным альтернативной страховой программы, заключавшейся в идее внедрения системы государственного страхования рабочих, обеспечивающей их в случае безработицы и потери трудоспособности, охватывающей также всех работников наемного труда и членов их семейств, инвалидов войны, и при этом все расходы на страхование должны нести государство и предприниматели.

Русско-японская (1904-1905 гг.) и Первая мировая (1914-1918 гг.) войны пополнили армию инвалидов, обрекающих свои семьи на нищету и бесправие. Следует отметить, что даже по признанию властей размеры пособий, выдававшихся военным инвалидам или их семьям, не «покрывали самых насущных расходов на прокормление и одежду» [11]. Для получения пособия инвалидам надо было доказать свое ранение, а на направленные запросы в полки ответы приходили через год и более. Лишь принятый в 1912 году закон о пенсиях изменил сам принцип, на котором строилась выдача нижним чинам денежной помощи от казны. Ранее это было нечто вроде милостыни, а с 1912 года это стало возмещением со стороны государства, при этом военные инвалиды имели право на пенсию независимо от их материального 
положения. И, если раньше это была благотворительность, теперь такая помощь стала компенсацией со стороны государства.

Заключение. На основании вышеизложенного можно сделать следующие выводы.

Появление первых государственных учреждений стало значительной вехой в формировании форм социальной и благотворительной деятельности, осуществляемой государством, а также придало организованный и мотивированный характер социальной деятельности. Однако такая помощь оказывалась очень ограниченно и зачастую несвоевременно. Но главная проблема заключалась в том, что только увечные военнослужащие могли относиться к инвалидам и претендовать на социальную помощь, в то время как другие люди, состояние здоровья которых невозможно восстановить, были лишены какой-либо поддержки. Их проблемы и насущные потребности игнорировались как государством, так и обществом.

Обобщая, можно сказать, что в дореволюционной России государственную социальную поддержку могли получать только чиновники и военные, причем, преимущественно высшие воинские чины, а на крестьян, рабочих и престарелых она не распространялась.

Зарождение цивилизованных трудовых отношений началось с 1912 года, когда был принят первый закон о страховании трудящихся от несчастных случаев.

Следует отметить, что в Российской империи, в отличие от Западной Европы, не сложилась устойчивая комплексная система благотворительной помощи, в которой государство, церковь и города выступали бы партнерами в деле благотворительности.

\section{Литература}

1. Монтескье Ш. Избранные произведения. - М.: Госполитиздат, 1955. - С. 416. [Электронный ресурс] - Режим доступа: http://padaread.com/?book=107662.

2. Белинский В.Г. Литературные мечтания // Полн. собр. соч. в 13 т. Т. 1. - М., 1953. - С. 37. [Электронный ресурс] - Peжим доступа: http://www.vgbelinsky.ru/texts/ books/13-1/articles-and-reviews/3/.
3. Ильинский B. Благотворительность в России: (История и настоящее положение). - СПб, тип. Имп. Человеколюбив. о-ва, 1908. [Электронный ресурс] - Режим доступа: https://search.rsl.ru/ru/record/01003748904.

4. Россия накануне Первой мировой войны. Статистико-документальный справочник. Благотворительность и общественное призрение. - М.: Изд-во: Самотека, 2008. [Электронный ресурс] — Режим доступа: http://istmat.info/node/166.

5. Щербинин П. П. Особенности социальной защиты ветеранов военной службы в Российской империи в XVIII - начале XX в. // Вестник ВГУ. Серия Гуманитарные науки. 2005. - №2. - C. 226-230.

6. Стародымов Н. Забота о военных инвалидах [Электронный ресурс] - Режим доступа: https://proza.ru/2010/12/03/278.

7. Жирнов E. Дело о великой краже пенсий // Коммерсантъ Деньги. - 2011. №24. - С. 49.

8. Прыжсов И.Г. Нищие на Святой Руси: материалы для истории общественного и народного быта в России / Соч. Н. Прыжова. М.: Тип. М.И. Смирновой, 1862. - С. 95. [Электронный ресурс] — Режим доступа: http://elib.shpl.ru/nodes/16442\#mode/inspect/ page/105/zoom/4.

9. Бахтиаров А.А. Брюхо Петербурга. Очерки столичной жизни; [Вступ. ст. и коммент. Ф.М. Лурье]. - СПб.: РИА «Ферт», 1994. - $221 \mathrm{c}$.

10. Полное собрание законов Российской Империи. Собрание Второе. Т. 36. Отд. 1. - СПб.: Тип. II Отделения Собственной Его Императорского Величества Канцелярии, 1981. [Электронный ресурс] — Peжим доступа: https://runivers.ru/bookreader/ book9934/\#page/148/mode/1up.

11. Обзор деятельности Алексеевского Главного комитета за десятилетие 19051915 гг. - Петроград, 1915. - С. 24. [Электронный ресурс] - Режим доступа: https:// search.rsl.ru/ru/record/01004202160.

\section{References}

1. Montesk'e Sh. Izbrannye proizvedenija [Selected works]. - Moscow: Gospolitizdat, 1955. — P. 416. [Jelektronnyj resurs] — URL: http://padaread.com/?book=107662. 
2. Belinskij V.G. Literaturnye mechtanija [Literary dreams] // Poln. sobr. soch. v 13 t. Vol.1. - Moscow, 1953. - P. 37. [Jelektronnyj resurs] — URL: http://www.vgbelinsky.ru/texts/ books/13-1/articles-and-reviews/3/.

3. Il'inskij $V$. Blagotvoritel'nost' v Rossii: (Istorija i nastojashhee polozhenie) [Charity in Russia: (History and present situation)]. Saint-Petersburg, tip. Imp. Chelovekoljubiv. o-va, 1908. [Jelektronnyj resurs] — URL: https://search.rsl.ru/ru/record/01003748904.

4. Rossija nakanune Pervoj mirovoj vojny. Statistiko-dokumental'nyj spravochnik. Blagotvoritel'nost' i obshhestvennoe prizrenie [Russia on the eve of the First world war. Statistical and documentary reference. Charity and public charity]. - Moscow: Izd-vo: Samoteka, 2008. [Jelektronnyj resurs] — P: http://istmat. info/node/166.

5. Shherbinin P.P. Osobennosti social'noj zashhity veteranov voennoj sluzhby v Rossijskoj imperii $\mathrm{v}$ XVIII - nachale XX v. [Features of social protection of military service veterans in the Russian Empire in the XVIII - early XX century] // Vestnik VGU. Serija Gumanitarnye nauki [Series Humanities]. — 2005. — №2. Pp. 226-230.

6. Starodymov N. Zabota o voennyh invalidah [Care of military invalids] [Jelektronnyj resurs] - URL: https://proza. $\mathrm{ru} / 2010 / 12 / 03 / 278$.
7. Zhirnov E. Delo o velikoj krazhe pensij [Case of Grand theft of pensions] // Kommersant Den'gi. - 2011. — №24. - P. 49.

8. Pryzhov I.G. Nishhie na Svjatoj Rusi: materialy dlja istorii obshhestvennogo i narodnogo byta $\mathrm{v}$ Rossii [Beggars in Holy Russia: materials for the history of social and national life in Russia] / Soch. N. Pryzhova. - Moscow: Tip. M.I. Smirnovoj, 1862. — P.95. [Jelektronnyj resurs] — URL: http://elib.shpl.ru/ nodes/16442\#mode/inspect/page/105/zoom/4.

9. Bahtiarov A. A. Brjuho Peterburga. Ocherki stolichnoj zhizni [The Belly of St. Petersburg. Essays on Metropolitan life]; [Vstup. st. i komment. F. M. Lur'e]. — Saint-Petersburg: RIA «Fert», 1994. - 221 p.

10. Polnoe sobranie zakonov Rossijskoj Imperii. Sobranie Vtoroe [Complete collection of laws of the Russian Empire. Second Meeting]. Vol. 36. Ed. 1. - Saint-Petersburg: Tip. II Otdelenija Sobstvennoj Ego Imperatorskogo Velichestva Kanceljarii, 1981. [Jelektronnyj resurs] — URL: https://runivers.ru/bookreader/ book9934/\#page/148/mode/1up.

11. Obzor dejatel'nosti Alekseevskogo Glavnogo komiteta za desjatiletie 1905-1915 gg. [Review of the activity of the Alekseevsky Main Committee for the decade of 19051915]. - Petrograd, 1915. - P. 24. [Jelektronnyj resurs] - URL: https://search.rsl.ru/ru/ record/01004202160. 


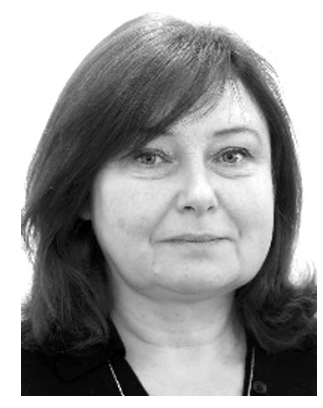

344038, г. Ростов-на-Дону, пл. Ростовского Стрелкового Полка Народного Ополчения, 2 2 Rostovskogo Strelkovogo Polka Narodnogo Opolcheniya sq., 344038, Rostov-on-Don, Russia E-mail: Elena.bona-mente@ yandex.ru

Шилкина Елена Леонидовна — доктор социологических наук, профессор Ростовского государственного университета путей сообщения. Специалист в области исследования социальной политики, государственного и муниципального управления.

Shilkina Elena Leonidovna - Doctor of Sociological Sciences, Professor, Rostov State Transport University. Specialist in the field of social policy research, state and municipal administration.

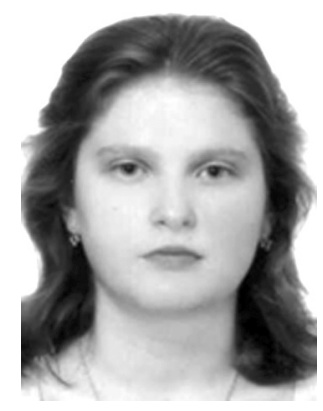

346500, г. Шахты, ул. Шевченко, 147

147 Shevchenko st., 346500, Shakhty, Russia

E-mail: samsidarena92@mail.ru

обслуживания и предпринимательства (филиала) «Донского государственного технического университета» в г. Шахты. Специалист в области исследования компонентов социокультурной среды как факторов, влияющих на социальное самочувствие людей с ограниченными возможностями здоровья.

Sidorova Daria Igorevna - Postgraduate Student, Institute of Service and Entrepreneurship (the Branch) of the Don State Technical University in Shakhty. Specialist in the field of research of components of the socio-cultural environment as factors affecting the social well-being of people with disabilities. 